Journal of Fisheries International 6(1): 6-12, 2011

ISSN: 1817-3381

(C) Medwell Journals, 2011

\title{
Reproductive Behaviour in Captive African Carp, Labeo parvus Boulenger, 1902 (Pisces: Cyprinidae)
}

\author{
${ }^{1,2}$ E. Montchowui, ${ }^{2} \mathrm{P}$. Laleye, ${ }^{3}$ J.C. Philippart and ${ }^{3} \mathrm{P}$. Poncin \\ ${ }^{1}$ National Higher School of Agricultural Sciences and Techniques of Ketou, \\ University of Abomey-Calavi, BP 95 Ketou, Republic of Benin \\ ${ }^{2}$ Laboratory of Hydrobiology and Aquaculture, \\ University of Abomey-Calavi, 01BP526 Cotonou, Republic of Benin \\ ${ }^{3}$ Behavioural Biology Unit, University of Liege, 22 Quai Van Beneden 4020 Liege, Belgium
}

\begin{abstract}
This study describes the reproductive behaviour of the Labeo parvus in aquarium. The breeding stock of L. parvus used in the present study, originated from the wild population of the Oueme river (Benin). Sexually mature fish were caught during their migration to their spawning pond, using gill nets from artisan fishermen. The experiments were conducted in a 540 and a $240 \mathrm{~L}$ aquaria. Reproductive behaviour was induced in 4 groups of two to six fish by means of a single injection of Ovaprim $\left(0.6 \mathrm{~mL} \mathrm{~kg}^{-1}\right.$ for females and $0.2 \mathrm{~mL} \mathrm{~kg}^{-1}$ for males). Behavioural data were recorded with a camera system $15 \mathrm{~min} \mathrm{~h}^{-1}$ during the day time between 8 and $19 \mathrm{~h}$. Sexual behaviour was observed in 2 groups. Seven spawning sequences were analysed involving one male and one female, undulating rapidly towards the water surface and descending slightly before freeing eggs and sperm in a rolling display. Some sneaking males were sometimes observed participating in spawning acts. The complete spawning sequence observed included nonsexual behaviours such as swimming and surfacing as well as sexual behaviours including synchronous swimming (very rapid swimming of two individuals side by side), the rolling display and mating.
\end{abstract}

Key words: Spawning behaviour, captive, aquarium, Labeo parvus, cyprinidae, eggs, Belgium

\section{INTRODUCTION}

Labeines are economically important food fish throughout the African continent (Skelton et al., 1991) where several species are candidates for aquaculture (Omoreigie, 2001; Rutaisire, 2003). The species Labeo parvus is widely distributed throughout West Africa (Leveque, 2003). It is a rheophilous fish which prefers running water in rocky habitats. In Benin, L. parvus is an important cyprinid fish in fisheries and is used as a popular food fish. Therefore, it is currently undergoing high fishing pressure.

There is limited quantitative information available on the life history of L. parvus. Data on Labeo species life histories suggest that they could be vulnerable to overfishing and they are obligatory total spawners with relatively small eggs and high fecundity (Tomasson et al., 1984; Skelton et al., 1991). Their eggs, embryos and larvae are particularly vulnerable to flash floods and associated siltation which can significantly reduce survival and fishery recruitment (Skelton et al., 1991). The reproductive biology and early life history of $L$. parvus were studied by Montchowui et al. (2009) but the reproductive behaviour of this species has never been described. According to Sadovy (1993), knowledge of the behavioural patterns and characteristics of spawning aggregations is important to fully understand the function of group spawning in a fish species.

This knowledge is also important for the implementation of proper management strategies with the aims of conserving economically important fish such as L. parvus and developing aquaculture.

In addition, the choice of mates and specific spawning as well as the timing and spatial co-ordination of gamete release may be of critical importance in the survival of progeny (Smith, 1991). The study focuses on the various sexual behaviours of $L$. parvus and their temporal succession during mating in aquarium.

The fish size, the water quality (often very turbid), the intensity and the speed of the water rising during the reproduction period and the spawning habitats in the Oueme river make any observation in the natural environment very difficult. Observation in an aquarium remains, the only simple means to study the reproductive behaviour of Labeo parvus.

Corresponding Author: Elie Montchowui, Laboratory of Hydrobiology and Aquaculture, University of Abomey-Calavi, 01BP526 Cotonou, Benin 


\section{J. Fish. Int., 6 (1): 6-12, 2011}

\section{MATERIALS AND METHODS}

The study was carried out over two seasons between July and October 2007 and July and October 2008 in the Laboratory of Hydrobiology and Aquaculture, University of Abomey-Calavi, Benin. The breeding stock of $L$. parvus used in the study originated from the population of the Oueme river (Benin). Sampling took place in July to September 2007, using gill nets from artisan fishermen. Sexually mature fish were caught during their migration to their spawning habitats. After capture, the fish were transferred to an oxygenated plastic container and transported to the Unit of Training and Research in Fish Farming in Cotonou.

On arrival at the fish farm facility, the fish were placed in rectangular concrete tanks supplied with gravity-fed spring water. The tanks were covered with nets to prevent the fish from jumping out. The fish were held in captivity and fed with artificial tilapia feed twice daily.

The experiments were carried out in a $540 \mathrm{~L}$ aquarium $(1.5 \times 0.6 \times 0.6 \mathrm{~m})$ and in a $240 \mathrm{~L}$ aquarium $(1 \times 0.4 \times 0.6 \mathrm{~m})$. In the $540 \mathrm{~L}$ aquarium, the bottom was covered with sand. A shelter $\left(900 \mathrm{~cm}^{2}\right)$ was suspended $25 \mathrm{~cm}$ above the bottom which was covered with a layer of gravel and green plastic plants (imitating Ceratophyllum), fixed in the sand. The bottom of the $100 \mathrm{~L}$ aquarium was only covered with sand (depth: $1 \mathrm{~cm}$ ). Each aquarium was equipped with a bullor for oxygenation. In the both aquaria, fish were maintained at a temperature of $27.9 \pm 0.5^{\circ} \mathrm{C}$, a dissolved oxygen content of $7.8 \pm 0.7 \mathrm{mg} \mathrm{L}^{-1}$ and a $\mathrm{pH}$ of $8.5 \pm 0.3$. The lighting was maintained constant: $12 \mathrm{~L} / 12 \mathrm{D}$.

Four groups of fish were formed, composed of one to two females and 1-4 males. Mature individuals were selected on the basis of morphological criteria: protruding genital papilla, dilated and bulging abdomen in females and presence of sperm in males determined by gentle abdominal pressure. The groups were formed in agreement with the sex-ratio observed in the natural environment: 1:1. The total length and weight (Table 1) of each fish were recorded before their transfer into the experimental aquaria.

As we were unable to obtain spontaneous mating, the selected fish received an injection of Ovaprim according to Montchowui et al. (2008) $\left(0.6 \mathrm{~mL} \mathrm{~kg}^{-1}\right.$ for females and $0.2 \mathrm{~mL} \mathrm{~kg}^{-1}$ for males) so as to induce and synchronise spawning. Ovaprim was injected during the night at $00 \mathrm{~h}$ (local time).

Fish were placed in the experimental aquaria the day before the behaviour was recorded. To recognise the fish, the females were marked with a slight ablation at the caudal fin. Each group was followed for 2 days. The behaviours were video-recorded using a video camera
Table 1: Average total length and weight $( \pm \mathrm{SD})$ of fish in the four groups

\begin{tabular}{lcrcc}
\hline \multicolumn{5}{c}{ of Labeo porvus } \\
Groups & $\begin{array}{c}\text { Length } \\
(\mathrm{cm})\end{array}$ & \multicolumn{1}{c}{$\begin{array}{c}\text { Weight } \\
(\mathrm{g})\end{array}$} & No. of fish & $\begin{array}{c}\text { No. of } \\
\text { spawning acts }\end{array}$ \\
\hline 1 & $19.5 \pm 1.0$ & $79.0 \pm 6.10$ & $2:\left(1+\right.$ and $\left.1 \sigma^{*}\right)$ & 6 \\
2 & $22.4 \pm 1.3$ & $116.8 \pm 21.7$ & $3:\left(1+\right.$ and $\left.2 \sigma^{*}\right)$ & 1 \\
3 & $14.6 \pm 2.2$ & $29.9 \pm 10.7$ & $4:\left(1+\right.$ and $\left.3 \sigma^{*}\right)$ & 0 \\
4 & $15.2 \pm 1.8$ & $34.6 \pm 9.20$ & $6:\left(2+\right.$ and $\left.4 \sigma^{*}\right)$ & 0 \\
\hline
\end{tabular}

(Sony digital video camera recorder, handycam DCRHC47E). Behavioural data were recorded for $15 \mathrm{~min} \mathrm{~h}^{-1}$ during day time from 8:00-19:00. The tapes were screened and the behavioural acts were encoded on a computer. Videotapes were analysed image by image during spawning acts. Sequencing and timing were obtained by typing keys on the computer keyboard using Noldus observer software (4.1). We focused on the main behavioural patterns of the encounters taking into account, the duration of swimming and feeding activities and the frequency of spawning as well as following or stimulating behaviours.

\section{RESULTS}

Description of sexual behaviour: The ethogram of Labeo parvus (Fig. 1) gathers nonsexual behaviours such as swimming, rest, foraging, surfacing and sexual behaviours such as synchronous swimming (which consists of a very rapid swimming of two individuals side by side), the rolling display and mating. Among the induced females, two (in group 1 made up of one male and one female and in group 2 made up of one female and two males) exhibited complete behavioural sequences leading to spawning acts in the majority associated with a quite visible release of oocytes. Five spawning events were recorded in day time between 8:00 and 19:00 in the group, comprising one male and one female. Incomplete sequences were raised in the same and other females without leading to spawning.

All spawning acts were recorded during day time. Courtship and spawning behaviour were never observed at night. The mating sequence type occurred in pairs. It always started with activation of courting by the male which turned several times around the female and stimulated the latter by nudging of the head to the female's sides or head (Fig. 1a, b). Sometimes the male gave a sharp blow of the nose, triggering the female's rapid swimming towards the surface followed by the male (Fig. 1c, d).

During this following behaviour, the male caught up with the female and the pair swam rapidly head against head in synchronous swimming towards the surface without breaking the surface (Fig. 1 e-g). High levels of following and stimulating behaviours preceded each mating act (Fig. 2). When the female was ready to spawn, 

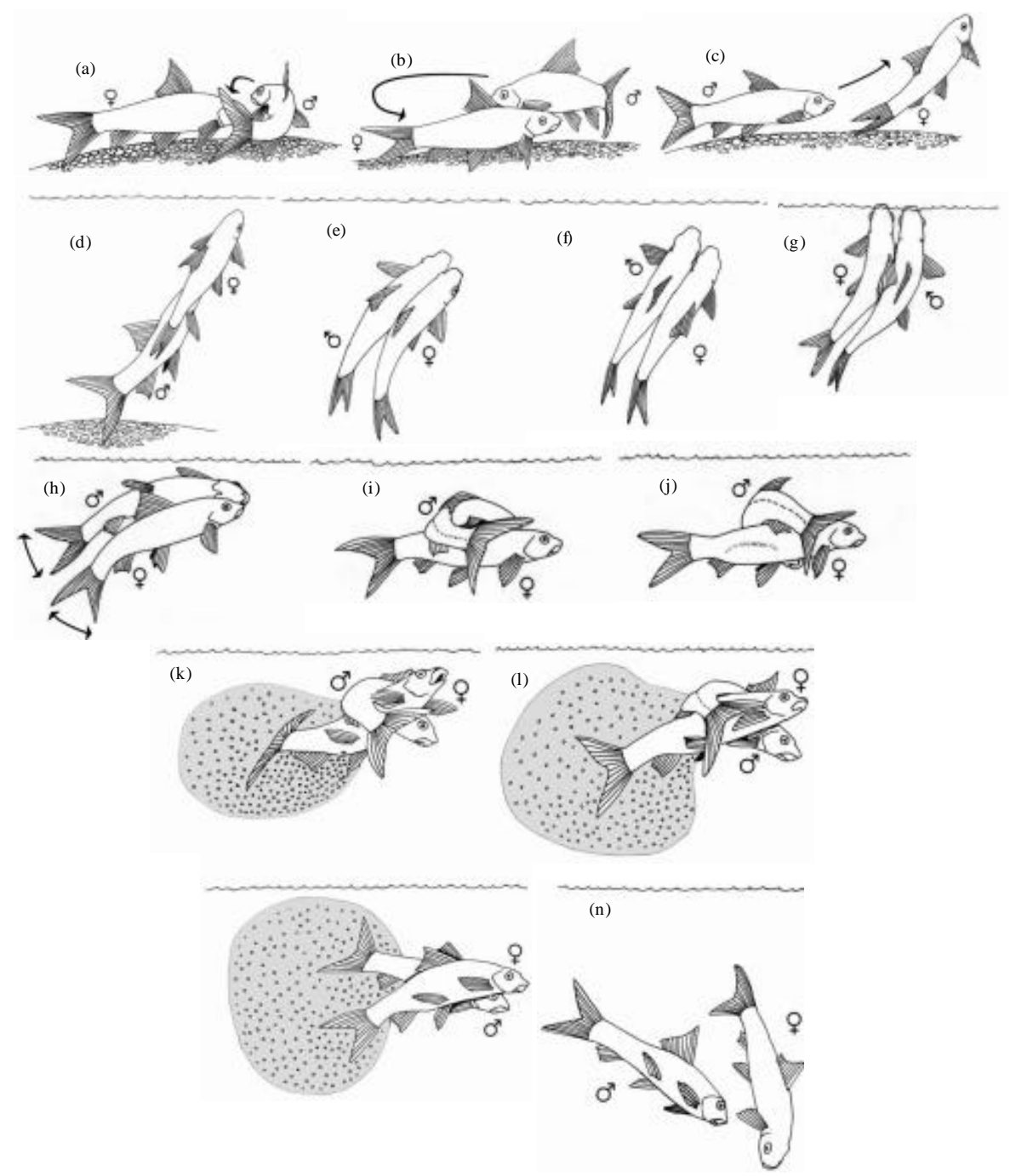

Fig. 1: Illustrations of spawning behaviours in Labeo parvis. a, b) stimulating behaviours; c, d) pursuit movements; e-g) synchronous swimming towards the water surface; $h$ ) trembling movement; $i, j$ ) rolling over the female by the male; $\mathrm{k}, 1$ ) spawning and $\mathrm{m}, \mathrm{n}$ ) post-spawning movements. The arrows indicate the direction of movement

the pair produced a few vibration movements then the male, located next to the partner during calm swimming, pressed his head against hers (Fig. 1h). The male, his body trembling, rolled over the female at her abdomen with his body with the female in a convex position (Fig. 1i, j). This rolling exerted a pressure on the female's abdomen, releasing the eggs (Fig. 1k, 1).

Then the male slipped under the female probably to release its sperm. This behaviour was observed without individuals swimming towards the water surface but near the bottom of the aquarium. The spawning pair then separated each taking its place on the bottom of the aquarium (Fig. $1 \mathrm{~m}, \mathrm{n}$ ). The eggs were swept along by the water-flow and deposited on the sand, covering the bottom of the aquarium. In the seven spawning sequences analysed, the female mated five times with a single male. In the other cases although, the behavioural sequence was initiated by a single male, it continued with one or two additional opportunistic males who stayed alongside the female when she released her ova. It was not possible to estimate the number of eggs released during each spawning act but once spawning ended, numerous fertilised eggs could be seen in the water. The fertilised eggs were non-adhesive. The membrane of the fertilised eggs soaked up water and formed a layer around the embryo. Hatching was observed after 11-14 h at $28-29^{\circ} \mathrm{C}$ water temperature, producing larvae that were reared in a nursery.

Behaviour over time: Figure 2 shows the changes over time of the main behaviours recorded in group 1, comprising one male and one female from light initiation 


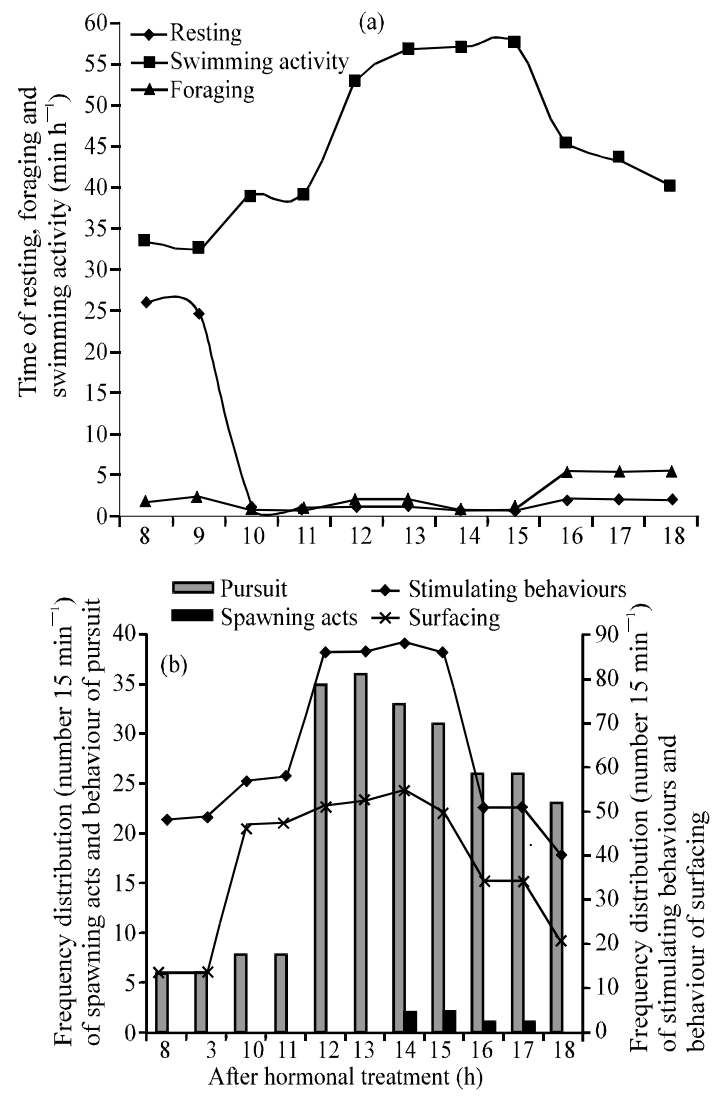

Fig. 2: Typical main behaviours recorded in the Labeo parvus (resting, swimming activity, foraging, stimulating, pursuit behaviour, surfacing behaviour and spawning acts) during a spawning day after hormonal treatment in group 1 comprising one female and one male

(8:00) until completion of egg laying (19:00). The swimming activity increased gradually until the mating period and declined thereafter. The resting and foraging activities declined with the approach of the mating period and then increased at the end of mating. The search for food by foraging fish was greater after the mating period than before.

Courting behaviours, pursuits by males and rising to the water surface of the pair of L. parvus sharply increased with the approach of and during the mating period and then faded.

The first mating was observed about $14 \mathrm{~h}$ after the hormone injection and spread over approximately $3 \mathrm{~h}$. Before mating, we noted the synchronous swimming between males and females as well as vibration movements and rolling over the female by the male. The frequencies and durations of these behaviours were relatively low and are not shown in Fig. 2.

\section{DISCUSSION}

This study describes for the first time, the reproductive behaviour and spawning tactics of $L$. parvus as a representative of the African labeines. It provides useful data for fisheries management and potential techniques for breeding this fish species in captivity.

The spawning period of $L$. parvus under captivity conditions in an experimental fish farm occurred from July to October and coincided with the reproductive season in the wild populations.

Pair-spawning appears to be the predominant L. parvus mating pattern as supported by behavioural observations. This mating system involves one male and one female undulating rapidly towards the water surface and descending slightly before freeing eggs and sperm in open water. A spawning group of three individuals (one female and two males) was observed when a sneaking male was sometimes seen participating in spawning acts by the main male.

The observations have been confirmed by further research. The mating system of $L$. parvus may be considered polygamous (Tuner, 1986), i.e., each male can mate successively with several females and each female can mate simultaneously or successively with several males. Given the difficulty of observing sperm emitted by the spawning males, only an analysis of eggs or larva paternity after fertilisation could provide information on the effective participation of each partner in the offspring. This type of research could be undertaken in the future as was done in Barbus barbus and Barbus meridionalis.

The size of testes in ripe males has often been used as an index of sperm competition and a method for predicting the fish mating system (Erisman and Allen, 2006). In general, a high Gonadosomatic Index (GSI) (i.e., $\geq 4$ ) in males is common in group-spawning fish species under intense sperm competition while low male GSI (0.5-3) is typical of pair-spawning fish where sperm competition is less important (Stockley et al., 1997; Petersen and Warner, 1998; Taborsky, 1998). The mean GSI of wild and captive male L. parvus (1.3 and 1.5, respectively, Montchowui) were similar to published values of GIS of fish characterised by external fertilisation, low sperm competition and pair spawning (Petersen and Warner, 1998).

It is evident that pair spawning appears to be the predominant mating pattern of $L$. parvus which does not appear to present aggressive behaviours (between males or between males and females) associated with reproduction. However, attacks between males and between males and females without biting, hunts between males or between females and males and blows of the 
head between males can sometimes be observed. The fertilised eggs are shed in open water in the aquarium and may then be pulled by the current and settle on any substrate. This observation confirms what was reported by Skelton et al. (1991) in the natural environment for African labeines. According to these researchers, Labeo spawning occurs in flowing water onto adjacent floodplains or flooded river banks where the eggs are shed over temporarily inundated vegetation. In the study, the nature of the substrates did not seem to influence sexual behaviour expression.

Although, spawning substrates were arranged in the aquaria, it appeared that the fish developed behaviours in which the spawners accelerated their swimming toward the water surface, independently of the spawning substrates. This behaviour results in the eggs being released in the water column. This type of behaviour is somewhat different from what occurs in European rheophilous cyprinids such as Chondrosoma nasus and Leuciscus cephalus which actively deposit their sticky eggs on a gravel bed.

It approaches the behaviour of gudgeon (Gobio gobio) or certain calm water cyprinids (Abramis brama) (Poncin et al., 1996) whose eggs are shed in the water column and then settle on the substrate (sand, gravel or aquatic vegetation). It is difficult to compare the reproductive behaviour of L. parvus and other African Labeo because data on the latter are unavailable.

Several schemes have been devised to group fish according to their choice of spawning site and degree of post-spawning care (Mills, 1991). Four categories of cyprinid behaviours have been identified: lithophils, psammophils, phytophils and pelagophils. According to the observations in aquarium, L. parvus could be classified among the psammophils which scatter their eggs on sand or near the roots of plants where the bottom is sandy again principally in flowing water and do not guard their eggs (Mills, 1991). Labeo parvus may be considered a non-guarder species since, no parental care was ever observed in aquarium.

The psammophils character of the reproduction observed in the study is different from that reported in Labeo umbratus (Potts et al., 2005). According to these researchers L. umbratus fits into the intermediate, phytolithophil reproductive guild. High mortality of fertilised eggs and embryos were observed in aquarium probably resulting from confinement conditions in aquarium. As fertilised eggs are not sticky and therefore do not adhere to any substrate, moving under the effect of the spawners' movement they are likely to be smothered by the grains of sand in aquarium or the spawners themselves. This may partly explain the high natural mortality rate $\left(0.96\right.$ year $\left.^{-1}\right)$ reported by Montchowui et al.
(2009) in the Oueme river for L. parvus. Indeed, deforestation is damaging Oueme river catchments and streams which formerly flowed for extended periods and are now characterised by brief flash-flood flows in which the water is heavily laden with silt. In these conditions, the fertilised eggs are either stranded by rapidly receding floodwaters or smothered by silt or both. Labeo parvus exhibited total spawning in aquaria under constant environmental conditions.

Each female spawned the totality of her eggs in the 1 day observation. The females examined at the end of the observation had empty ovaries. This confirms the observation regarding the gonadal maturation stages and the gonadosomatic indexes in wild populations (Montchowui et al., 2008) which undergo an abrupt decrease during the breeding season, suggesting a single spawning (Rinchard and Kestemont, 1996). These results suggest that L. parvus females might release one batch of eggs a year. The single and total spawning mode of reproduction is also supported by the diameter-frequency distribution pattern of oocytes showing that $L$. parvus ovaries belong to the synchronous ovary type. Total spawning is not an uncommon phenomenon among cyprinid fish in the wild, e.g., in Labeo cylindricus (Weyl and Booth, 1999) and Chondrostoma nasus.

According to Abou-Seedo and Dadzie (2004), the phenomenon of synchronous oocyte development with a single spawning may be related to the unstable nature of the habitat of the species hence, the need to spend as little time as possible on the spawning grounds. Labeo parvus presents a periodic reproductive behaviour, probably as an adaptation to the instability of its natural habitat, mostly due to intense environmental variability related to the seasonality of rainfall and river discharge. Hormonal induction of spawning has been used previously to observe the reproductive behaviour of several species when spontaneous mating is hard to obtain in captivity (Poncin et al., 1996, 2002). Given that sexual behaviour was not observed in individuals not stimulated in this study, it is impossible to estimate the influence of hormonal induction on the expression of behaviour. We did not observe spawning in some groups although, the fish were induced by an injection of Ovaprim. It is difficult to explain the low reproductive rate of spawners. Insufficient maturity or stress related to short acclimation time in aquaria could be the cause. An influence of the low number of courting males may also explain the low reproductive rate of spawners. Indeed in the groups composed of $>1$ male, the female is abandoned. The males spend their time quarreling by blows of the head and pursuits. Any attempt to initiate sexual behaviour of a male with the female is immediately disrupted by other males. Further, research on the 
influence of the number of courting males could be undertaken in the future as was done in Barbus barbus.

\section{CONCLUSION}

The mating system of Labeo parvus was polygamous, with females spawning $>1$. It was not possible to estimate the number of eggs released during each spawning act. One spawning ended in numerous fertilised eggs being shed in the water. The fertilised eggs were non-adhesive. The membrane of fertilised eggs soaks up water and forms a layer around the embryo. Hatching was observed after $11-14 \mathrm{~h}$ at $27-29^{\circ} \mathrm{C}$ water temperature, producing larvae that were reared in a nursery.

\section{ACKNOWLEDGEMENTS}

This research received financial support from the Belgian Technical Cooperation (CTB), the Agence Universitaire de la Francophonie (AUF) and from Project FNRS-FRFC 2.4569.06. We thank Dr. M. Denoel, P. Humpers and V. Galloy for their technical assistance and A.M. Massin for drawing Fig. 1.

\section{REFERENCES}

Abou-Seedo, F. and S. Dadzie, 2004. Reproductive cycle in the male and female grey mullet, Liza klunzingeri in the Kuwaiti waters of the Arabian Gulf. Cybium, 28: 97-104.

Erisman, B.E. and L.G. Allen, 2006. Reproductive behaviour of a temperate serranid fish, Paralabrax clathratus (Girard), from Santa Catalina Island, California, U.S.A. J. Fish Biol., 68: 157-184.

Leveque, C., 2003. Cyprinidae. In: The Fresh and Brackish Water Fishes of West Africa, Paugy, D., C. Leveque and G.G. Teugels (Eds.). Faune et Flore Tropicales 40. IRD, MNHN and Musee Royal de l'Afrique Centrale, France, pp: 322-436.

Mills, C.A., 1991. Reproduction and Life History. In: Cyprinid Fishes: Systematics, Biology and Exploitation, Winfield, I.J. and J.S. Nelson (Eds.). Chapman and Hall, London. ISBN: 0-412-34920-5, pp: 483-508.

Montchowui E., P. Laleye, J.C. Philippart and P. Poncin, 2008. Hormonal induction of ovulation in the African carp: Labeo parvus Boulenger, 1902 (Teleostei: Cyprinidae). Proceedings of the 4th International Conference of the Pan African Fish and Fisheries Association, Sept. 22-26, Addis Ababa, Ethiopia, pp: $184-184$.
Montchowui, E., P. Laleye, J. Moreau, J.C. Philippart and P. Poncin, 2009. Population parameters of African carp, Labeo parvus Boulenger, 1902 (Pisces: Cyprinidae) in the Ouémé River in Bénin (West Africa). North-West. J. Zool., 5: 26-33.

Omoreigie, E., 2001. Utilization and nutrient digestibility of mango seeds and palm kernel meal by juvenile Labeo senegalensis (Antheriniformes: Cyprinidae). Aqua. Res., 32: 681-687.

Petersen, C.W. and R.R. Warner, 1998. Sperm Competition in Fishes. In: Sperm Competition and Sexual Selection, Birkhead, T. and A. Moller (Eds.). Academic Press, London, UK., ISBN : 0-12-100543-7, pp: 435-463.

Poncin, P., J.C. Philippart and J.C. Ruwet, 1996. Territorial and non-territorial spawning behaviour in the bream. J. Fish Biol., 49: 622-626.

Poncin, P., P. Petitfrère, P. Vandewalle and J.C. Ruwet, 2002. The reproductive behaviour of the African catfish Heterobranchus longifilis (Siluriformes, Clariidae) in an aquarium-Preliminary results. Belg. J. Zool., 132: 35-39.

Potts, W.M., A.J. Booth, T. Hecht and T.G. Andrew 2005. Reproductive biology of a riverine cyprinid, Labeo umbratus (Teleostei: Cyprinidae), in small South African reservoirs. Afr. J. Aquat. Sci., 30: 147-155.

Rinchard, J. and P. Kestemont, 1996. Comparative study of reproductive biology in single and multiple spawned cyprinid fish. 1. Morphological and Histological features. J. Fish Biol., 49: 883-894.

Rutaisire, J., 2003. The reproductive biology and artificial breeding of Ningu Labeo victorianus (Pisces: Cyprinidae). Ph.D. Thesis, Rhodes University, Grahamstown, South Africa.

Sadovy, Y., 1993. Size, composition and spatial structure of the annual spawning aggregation of the red hind, Epinephelus guttatus. Pisces: Serranidae, 2: 399-406.

Skelton, P.H., D. Tweddle and P.B.N. Jackson, 1991. Cyprinids in Africa. In: Cyprinid Fishes: Systematics, Biology And Exploitation, Winfield, I.J. and J.S. Nelson, (Eds.) Chapman and Hall, London, pp: 211-239.

Smith, R.J.F., 1991. Social Behaviour, Homing and Migration. In: Cyprinid Fishes: Systematics, Biology and Exploitation, Winfield, I.J. and J.S. Nelson (Eds.). Chapman and Hall, London, UK., ISBN: 0-412-349205, pp: 509-529.

Stockley, P., M.J.G. Gages, G.A. Parker and A.P. Moller, 1997. Sperm competition in fishes: The evolution of testis size and ejaculate characters. Am. Natural, 149: 933-954. 
Taborsky, M., 1998. Sperm competition in fish: Bourgeois males and parasitic spawning. Trends Ecol. Evol., 13: $222-227$.

Tomasson, T., J.A. Cambray and P.B.N. Jackson, 1984. Reproductive biology of four large riverine fishes (Cyprinidae) in a man made lake, Orange River, South Africa. Hydrobiologia, 112: 179-195.
Tuner, G., 1986. Teleost Mating Systems and Strategies. In: The Behaviour of Teleost Fishes, Pitcher, T. (Ed.). Croom Helm, London, UK., ISBN: 9780412429309 , pp: 253-274.

Weyl, O.L.F. and A.J. Booth, 1999. On the life-history of a cyprinid fish, Labeo cylindricus. Environ. Biol. Fish., 55: 215-225. 